\title{
TWO SIDES OF THE SAME RUPEE? COMPARING DEMAND FOR MICROCREDIT AND MICROSAVING IN A FRAMED FIELD EXPERIMENT IN RURAL PAKISTAN*
}

\author{
Uzma Afzal, Giovanna d'Adda, Marcel Fafchamps, Simon Quinn and Farah Said
}

\begin{abstract}
We use a field experiment to test whether saving and borrowing satisfy demand for lump-sum accumulation from regular deposits. Inspired by ROSCAs, we offer different credit and saving contracts to subjects. We find that individuals often accept both credit and saving contract across experimental waves. This behaviour can be rationalised by assuming that individuals seek lump-sum payments and struggle to hold savings. Structural estimation of this model accounts for the behaviour of $75 \%$ of participants. Of these, two-thirds have high demand for lump-sum accumulation but savings difficulties. These results imply that the distinction between microlending and microsaving is largely illusory.
\end{abstract}

\subsection{Saving and Borrowing: An Illusory Distinction?}

Saving and borrowing are often considered to be diametrically different behaviour: the former is a means to defer consumption; the latter, a means to expedite it. However, this distinction collapses under two important conditions that are common in developing countries. First, many in poor communities struggle to hold savings over time, e.g., because of external sharing norms (Platteau, 2000; Anderson and Baland, 2002) or internal lack of self-control (Ashraf et al., 2006; Gugerty, 2007; Bernheim et al., 2015; John, 2015; Kaur et al., 2015). Second, the poor sometimes wish to incur lumpy expenditures - for instance, to purchase an 'indivisible durable consumption good' (Besley et al., 1993, p. 792) or take advantage of a 'high-return but lumpy and illiquid investment opportunity' (Field et al., 2013, p. 2200).

If these two conditions hold - as they clearly do in many poor communities - then the same individual may prefer to take up a saving product than to refuse it and, simultaneously, prefer to accept a loan product than to refuse it. This demand has nothing to do with deferring or expediting consumption. Rather, both products provide a valuable mechanism for accumulating a lump-sum at some point in time. In doing so, each product meets the same demand for a regular schedule of deposits and a lump-sum withdrawal. No longer do saving products and borrowing products stand in

* Corresponding author: Simon Quinn, Department of Economics, University of Oxford, Manor Road Building, Oxford OX1 3UQ, UK. E-mail: simon.quinn@economics.ox.ac.uk.

This project was funded by the UK Department for International Development (DFID) as part of the programme for Improving Institutions for Pro-Poor Growth (iiG). The project would not have been possible without the support of Dr Rashid Bajwa and Tahir Waqar at the National Rural Support Programme and Dr Naved Hamid at the Centre for Research in Economics and Business at the Lahore School of Eonomics. We received outstanding assistance in Sargodha from Rachel Cassidy, Sharafat Hussain, Tazeem Khan, Pavel Luengas-Sierra, Saad Qureshi and Ghulam Rasool. We thank audiences at the Berlin Social Science Center, the University of Houston, the University of Maryland, NEUDC, Stanford University, the South Asia Microfinance Network Regional Conference and the University of Oxford. We also thank Joshua Blumenstock, Justin Sandefur and Amma Serwaah-Panin for their useful comments. Our pre-analysis plan is registered at the Registry for International Development Impact Evaluations (RIDIE-STUDY-ID528385f5d3034). 
stark juxtaposition to each other; they are, rather, two sides of the same coin. Several authors have suggested this kind of motivation for the adoption of microlending contracts in developing countries. Rutherford (2000) contrasts 'saving up' (setting aside funds to receive a lump sum) and 'saving down' (receiving a lump sum that is repaid in regular instalments); the latter behaviour is termed by Morduch (2010) as 'borrowing to save' (Collins et al., 2009). Bauer et al. (2012, p. 1119) support this 'alternative view of microcredit', showing 'a robust positive correlation between having present-biased preferences and selecting microcredit as the vehicle for borrowing'.

In this article, we run a framed field experiment in rural Pakistan to test directly whether microlending serves a microsaving objective. We take a simple repayment structure - loosely modelled on the idea of a ROSCA (rotating savings and credit association) and offer it as an individual microfinance product. We offer the product three times to each subject, randomly varying the time of repayment and the repayment amount. Namely, the product can take the form of a microcredit or of a microcredit contract and the repayment amount can either be equal, $10 \%$ smaller or $10 \%$ larger than their total contribution. Together, these two sources of variation allow us to test between a 'traditional' benchmark model of microfinance in which participants prefer either to borrow or to save and an alternative model in which participants welcome both borrowing and savings contracts as opportunities for lumpsum payments.

We find that the same pool of respondents simultaneously have a demand both for microcredit and for microsaving. Indeed, over the course of the three experiment waves, 277 of the 709 respondents were offered both a credit contract and a savings contract; of these, $148(53 \%)$ accepted both forms of contract. Demand for our microfinance product is generally high, with approximately $65 \%$ take-up. Sensitivity to interest rate and day of payment is statistically significant but not large in magnitude.

We extend this analysis using a structural estimation to quantify the heterogeneity in clients' deep preferences. Specifically, we build competing structural models of demand for microfinance products, and we use a non-parametric maximum likelihood method to estimate the proportion of respondents adhering to each model. Our structural framework rationalises the behaviour of $75 \%$ of the participants. Of these rationalised participants, two-thirds behave as if they have high demand for lump-sum accumulation coupled with savings difficulties. Together, the results imply that the distinction between microlending and microsaving is largely illusory. Rather, many people welcome microcredit and microsavings products for the same reason: that each provides a mechanism for regular deposits and a lump-sum payment.

\subsection{Daily Deposits and the Context of the Experiment}

We implement our experiment using a fixed schedule of daily deposits. The focus on daily deposits is motivated by the nature of the study population, which is composed of urban and peri-urban households who are not, as a rule, in permanent employment. As we document in the data section, a large share of subject households have a daily income flow - typically from casual wage labour, self-employment in a small business (e.g. retail shop, personal services, rickshaw driver), or the sale of dairy farm products. Even among the $28 \%$ of households where the household head or spouse has a 
permanent wage job, we observe other more frequent sources of cash inflow. By opting for a frequency of deposits that matches the periodicity of income, we seek to maximise the commitment value of the microfinance product we offer. ${ }^{1}$

Daily deposit schedules are a relatively common feature of microfinance products in many countries - particularly those targeted at clients who are self-employed. In particular, they are the defining feature of 'daily collectors' - informal mobile bankers who allow daily deposits and withdrawals in many countries, particularly in West Africa. ${ }^{2}$ These mobile bankers provide a critically important financial service for many poor households. For example, in a sample drawn from the outskirts of Cotonou, Somville (2011) finds that approximately one third of positive incomeearners make such payments (Aryeetey and Steel, 1995; Aryeetey and Udry, 1997). Similarly, Ananth et al. (2007) describe a small survey of vegetable vendors in Chennai. They find that approximately $50 \%$ of respondents had engaged in very short-term borrowing for at least a decade, including the use of daily repayment products to support working capital; this can even involve taking a loan in the morning to purchase vegetables from a wholesaler, then repaying the loan on the same afternoon from daily sales. ${ }^{3}$

Formal organisations sometimes play a similar role. Most prominently, the NGO Safe Save provides 'passbook savings' accounts, in which clients may make deposits and withdrawals at their house when a collector calls each day (Armendáriz de Aghion and Morduch, 2005; Dehejia et al., 2012; Islam et al., 2013; Laureti, 2015). ${ }^{4}$ Similarly, Ashraf et al. (2003) document Jigsaw Development's 'Gold Savings' account, in which daily instalments were used to repay purchases of gold; the authors also describe the 'Daily Deposit Plan', the most popular account of Vivekananda Sevakendra O Sishu Uddyon, an NGO operating in West Bengal. ${ }^{5}$

Daily deposit schedules are also facilitated by many ROSCAs. For example, Rutherford (1997) studied 95 loteri samities in the slums of Dhaka, finding that approximately two-thirds collected payments daily. ${ }^{6}$ Work in other contexts finds the proportion to be much smaller but certainly not negligible. For example, Adams and Canavesi de Sahonero (1989) find that $15 \%$ of sampled pasankus in Bolivia used daily repayments (particularly those used by self-employed women), Aliber (2001) reports that $10 \%$ of stockvels in Northern Province used daily payments (again, particularly those

1 The 'hand-to-mouth' phenomenon need not be restricted to poor households with a daily income: for example, Kaplan et al. (2014, p. 79) argue that a substantial proportion of households in developed economies are 'wealthy hand-to-mouth', in the sense of holding 'little or no liquid wealth, whether in cash or in checking or savings accounts, despite owning sizable amounts of illiquid assets'.

${ }^{2}$ Such collectors are also known as 'tontinier' in Benin, 'susu' in Ghana, 'esusu' in Nigeria and 'deposit collectors' in parts of India (Somville, 2011).

3 See also Rutherford (2000), who discusses the same practice in Andhra Pradesh.

4 See also http://www.safesave.org/products.

${ }^{5}$ Of course, even banks without formal daily payment products may still facilitate daily deposits. For example, Steel et al. (1997) describe a savings and loan company in Ghana that would encourage selfemployed women to deposit proceeds each evening and then withdraw as necessary the following morning.

${ }^{6}$ Rutherford's impression from those loteri samities matches closely the key hypothesis that we test in this paper. Rutherford (1997, p. 367) writes: "The most common answer to the question "why did you join this samity?" was "to save, because it is almost impossible to save at home." Follow-up questions showed that the intermediation of those savings into a usefully large lump sum is also important. But it is not true that most members want to take that lump sum as a loan. ... There is little doubt in my mind that the respondents understand these samities as being, primarily, about savings rather than about loans'. 
used by the self-employed), Tanaka and Nguyen (2010) report a figure of $8.8 \%$ of huis in South Vietnam and Kedir and Ibrahim (2011) report $2.8 \%$ for Ethiopian equbs. ${ }^{7}$

Approximately $80 \%$ of respondents are familiar with the concept of a ROSCA (known in Pakistan as a 'savings committee'). Of these, about two-thirds have ever participated in one. This is important for ensuring that our repayment structure resonates with a well-understood local financial product. Of the respondents who had ever participated in a committee, $90 \%$ report that the committee required payments on a monthly basis; only $4 \%$ of respondents reported a committee with daily deposits. Anecdotal evidence suggests that daily instalment structures are nonetheless quite common in Pakistan Punjab through informal providers, including in the locations of the study. Often, this involves 'commission agents' (arthis), who can offer short-term loans to retailers to enable the purchase of stock. For small shopkeepers and street vendors, this can involve a daily loan to be paid back at the close of business (sometimes as a percentage of daily sales). ${ }^{8}$

In sum, commitment products with daily repayments are common in many developing countries. In Pakistan, such products are hardly ever offered as ROSCAs, and appear to have fallen beneath the radar of microfinance institutions. Nonetheless, the demand for daily borrowing through informal providers indicates that there are many Pakistanis with extremely short-term cash flow management needs. In this article, we offer an original solution to these problems that offers an ideal way to test the value of having regular deposits towards an achievable goal.

We deliberately run the experiment using clients of a microcredit programme, that is, using a subject population with a demonstrated demand for credit. If this population displays as much interest in a commitment saving contract as in borrowing, this will suggest that their demand for credit may partly reflect a demand for commitment saving. Finally, to make the demonstration even more salient, we choose a short credit and saving duration - i.e., one week - in order to reduce the attractiveness of credit as an intertemporal smoothing device: if borrowing only serves to accelerate consumption or investment, we expect few takers for credit contracts with a one week maturation period and a high interest rate.

\subsection{Recent Research on Microfinance}

Our key empirical result - that, for a high proportion of microfinance clients, credit and savings can act as substitutes - is useful for understanding recent research on microfinance. Growing empirical evidence suggests that savings products can be valuable for generating income and for reducing poverty (Burgess and Pande, 2005; Dupas and Robinson, 2013; Brune et al., 2016). Standard microcredit products - with high interest rates and immediate repayments - increasingly seem unable to generate enterprise growth (Karlan and Zinman, 2011; Banerjee et al., 2015). In contrast, recent evidence shows that an initial repayment grace period increases long-run profits of

\footnotetext{
7 See also Handa and Kirton (1999), who report that $6 \%$ of Jamaican ROSCAs - known as 'partners' meet more frequently than once per week.

${ }^{8}$ See Haq et al. (2013), who describe the role of arthis in longer-term lending for agricultural commodity markets.
} 
microfinance clients by facilitating lumpy investments (Field et al., 2013). Indeed, a growing literature suggests that part of the attraction of microcredit is as a mechanism to save - whether to meet short-term liquidity needs (Kast and Pomeranz, 2014), to resist social or familial pressure (Baland et al., 2011), or as a commitment device against self-control problems (Collins et al., 2009; Bauer et al., 2012). ${ }^{9}$

We make several contributions to this literature. First, we introduce a new experimental design which, to our knowledge, is the first to allow a direct test between demand for microsaving and demand for microcredit. Second, our design generates new empirical results showing that the same respondent population has high demand for both microcredit and microsaving (Gross and Souleles, 2002; Collins et al., 2009; Morduch, 2010; Kast and Pomeranz, 2014; Laureti, 2015). Indeed, the same individuals often take up either contracts within the span of a couple of weeks. Third, we make a methodological contribution through our structural framework. Specifically, we parameterise a Besley et al. (1993) model to test the demand for (latent) lumpy purchases. We show how to nest this model in a discrete finite mixture framework to allow for maximal heterogeneity in individual preferences.

The article proceeds as follows. In Section 1, we provide a conceptual framework. This motivates the experimental design, which we describe in Section 2. We report regression results in Section 3. Section 4 parameterises the conceptual framework for structural analysis and presents the non-parametric maximum likelihood estimator. We discuss identification and show structural results. Section 5 concludes.

\section{Conceptual Framework}

This Section develops a simplified theoretical framework; this framework motivates the experiment and serves as a foundation for the structural analysis. We use a dynamic model in which we introduce a preference for infrequent lump-sum payments. We begin with a benchmark model in which individuals either demand a savings product or a loan product, but not both. We then show how this prediction changes when we impose that people cannot hold cash balances, e.g., because of self-commitment problems due to time inconsistency.

We start by noting that the simple credit and savings products used by the poor can be nested into a generalised ROSCA contract. The contract spans periods $t \in\{1, \ldots, T\}$ and has a single payout period, $p \in\{1, \ldots, T\}$. In periods $t \neq p$, the participant pays an instalment of $s$; in period $t=p$, the participant receives a lump sum equal to $(T-1) \times s \times(1+r)$. Parameter $r$ represents the interest rate of the contract, which can be positive or negative. In a standard ROSCA contract, $r=0$ and $p$ is determined through random selection. In a typical (micro) credit contract with no grace period, $r<0$, the lump sum is paid in period $p=1$, and instalments $s$ are made in periods 2 to $T$. A typical commitment savings contract (e.g. retirement contribution) is when $r>0$, the lump-sum is paid in the last period $(p=T)$, and instalments $s$ are made from period 1 to period $(T-1)$.

\footnotetext{
${ }^{9}$ Mullainathan and Shafir (2009) discuss the role of lottery tickets as commitment savings devices analogously to random ROSCAs. See also Basu (2016), who provides a theoretical model in which sophisticated time-inconsistent agents find it welfare-enhancing both to borrow and to save simultaneously.
} 
We first consider a benchmark utility maximising framework. We begin by assuming:

(i) that there is no particular demand for lumpy consumption; and

(ii) that individuals can hold positive cash balances between time periods.

To illustrate the predictions that this model makes about the demand for generalised ROSCA contracts, consider a short-term T-period model with cash balances $m_{t} \geq 0$. Each individual is offered a contract with an instalment level $s$, a payment date $p$, and an interest rate $r$. The contract is therefore completely characterised by the triple $(s, p, r)$. The individual chooses whether or not to take up the contract, which is then binding.

Let $y$ be the individual's cash flow from period 1 to $T .{ }^{10}$ The value from refusing a contract $(s, p, r)$ is:

$$
V_{r}=\max _{\left\{m_{t} \geq 0\right\}} \sum_{t=1}^{T} \beta^{t} \times u_{t}\left(y_{t}+m_{t-1}-m_{t}\right),
$$

where $u_{t}(\cdot)$ is an instantaneous concave utility function (which may be time-varying), $\beta \leq 1$ is the discount factor, and $m_{0} \geq 0$ represents initial cash balances. Given the short time interval in the experiment, $\beta$ is approximately 1 . Hence if $u_{t}(\cdot)=u(\cdot)$, the optimal plan is approximately to spend the same on consumption in every period. In this case, demand for credit or saving only serves to smooth out fluctuations in income.

The more interesting case is when the individual wishes to finance a lumpy expenditure (e.g. to bulk-purchase food products, buy a consumer durable, pay rent, or invest for a business). We treat the purchase of a lumpy good as a binary decision taken in each period $\left(L_{t} \in\{0,1\}\right)$ and we use $\alpha$ to denote the cost of the lumpy good. We consider a lumpy expenditure roughly commensurate to the lump-sum payment: $\alpha \approx(T-1) \times s \times(1+r)$. Following Besley et al. (1993), we model the utility from lumpy consumption $L=1$ and continuous consumption $c$ as $u(c, 1)>u(c, 0)$. Without the generalised ROSCA contract, the decision problem becomes:

$$
V_{r}=\max _{\left\{m_{t} \geq 0, L_{t}=\{0,1\}\right\}} \sum_{t=1}^{T} \beta^{t} \times u\left(y_{t}+m_{t-1}-m_{t}-\alpha \times L_{t}, L_{t}\right) .
$$

With the ROSCA contract, the value from taking the contract $(s, p, r)$ is:

$$
\begin{aligned}
& V_{c}=\max _{\left\{m_{t} \geq 0, L_{t}=\{0,1\}\right\}}\left\{\sum_{t \neq p}\left[\beta^{t} \times u\left(y_{t}-s+m_{t-1}-m_{t}, L_{t}\right)\right]\right. \\
&\left.+\beta^{p} \times u\left[y_{p}+(T-1) \times s \times(1+r)+m_{p-1}-m_{p}-\alpha, L_{p}\right]\right\} .
\end{aligned}
$$

If $\alpha$ is not too large relative to the individual's cash flow $y_{t}$, it is individually optimal to accumulate cash balances to incur the lumpy expenditure, typically in the last period $T$. Otherwise, the individual gets discouraged and the lumpy expenditure is either not made, or delayed to a time after $T$. Taking up the contract increases utility if it enables consumers to finance the lumpy expenditure $\alpha$. For individuals who would have saved on their own to finance $\alpha$, a savings contract with $r>0$ may facilitate savings by

\footnotetext{
${ }^{10}$ We could make $y_{t}$ variable over time but doing so adds nothing to the discussion that is not already well known. Hence we ignore it here.
} 
reducing the time needed to accumulate $\alpha .{ }^{11}$ Hence we expect some take-up of savings contracts with a positive return.

A credit contract allows incurring the lumpy expenditure right away and saving later. Hence, for a credit contract with a positive interest charge to be attractive, the timing of $L_{t}=1$ must be crucial for the decision maker. Otherwise the individual is better off avoiding the interest charge by saving in cash and delaying expenditure $L$ by a few days. This is the reason that - as discussed earlier - we do not expect such an individual to be willing to take up both a credit and a savings contract at the same time: either the timing of $L_{t}=1$ is crucial or it is not.

In addition to the above observations, the presence of cash balances also generates standard arbitrage results. The predictions from this benchmark model can be summarised as follows:

(i) Individuals always refuse savings contracts $(p=T)$ with $r<0$ (i.e. a negative return). This is because accepting the contract reduces consumption by $T \times s \times r$. Irrespective of their smoothing needs, individuals can achieve a higher consumption by saving through cash balances.

(ii) Individuals always accept credit contracts $(p=1)$ with $r>0$ (i.e. a negative interest charge). This is because, irrespective of their smoothing needs, they can hold onto $T \times s$ to repay the loan in instalments and consume $T \times s \times r>0$.

(iii) Individuals refuse credit contracts $(p=1)$ with a large enough cost of credit $r<0$. This follows from the concavity of $u(\cdot)$ : there is a cost of borrowing so high that individuals prefer not to incur expenditure $L$.

(iv) Individuals accept savings contracts $(p=T)$ with a high enough return $r \geq 0$. This too follows from the concavity of $u(\cdot)$.

(v) The same individual will not demand both a savings contract (with a positive return $r>0$ ) and a credit contract (with a non-negative interest cost $r \leq 0$ ).

Things are different when people use credit or ROSCAs as a commitment device to save. Within our framework this is most easily captured by assuming that people cannot hold cash balances (that is, $m_{t}=0$ ). It is of course possible to construct a more complete model in which $m_{t}=0$ is not an assumption but an equilibrium outcome. ${ }^{12}$ This would make the model more complicated without adding any new insight. The key idea is that when individuals cannot accumulate cash balances on their own, for whatever the reason, then the only way for them to make the lumpy purchase is to take the $(s, p, r)$ contract. This creates a wedge between $V_{r}$ and $V_{c}$ that increases the likelihood of take-up: the contract enables the individual to incur the lumpy expenditure, something they could not do on their own. If the utility gain from buying the lumpy good is high, individuals are predicted to accept even contracts that would always be refused by someone who can hold cash balances - such as savings contracts with a negative return or credit contracts with a high interest charge.

\footnotetext{
11 Offering a positive return on savings may even induce saving by individuals who otherwise find it optimal not to save: McKinnon (1973).

12 Example of micro-foundations include quasi-hyperbolic preferences as in Ambec and Treich (2007); pressure from the spouse as in Anderson and Baland (2002) and Somville (2014); pressure from nonhousehold members as in Goldberg (2011).
} 
Take-up predictions under the alternative model can thus be summarised as follows:

( $i$ ) Time of payment $(p)$ is irrelevant: if an individual accepts a credit contract with $s$ and $r$, (s) he also accepts a savings contract with the same $s$ and $r$.

(ii) Individuals may accept savings contracts $(p=T)$ with $r<0$ (i.e. a negative return); the arbitrage argument no longer applies. Individuals refuse savings contracts $(p=T)$ with a low enough return $r$. This again follows from the concavity of $u(\cdot)$ : the only difference is that now the threshold interest rate $r$ may be negative.

(iii) Individuals do not always accept credit contracts $(p=1)$ with $r>0$ (i.e. a negative interest charge). This is because they cannot hold onto $(T-1) 9 s$ to repay the loan in instalments. Individuals refuse credit contracts $(p=1)$ with a large enough cost of credit $r<0$. This prediction still holds since it follows from the concavity of $u(\cdot)$.

\section{Experiment}

\subsection{Experimental Design}

We implement a stylised version of this theoretical model as a field experiment. At the beginning of each week, on day 0 , each participant is offered one of 12 different generalised ROSCA contracts, where the type of contract offered is determined by the random draw of cards. ${ }^{13}$ The 12 contracts differ by:

(i) timing of lump-sum payment $p$; and

(ii) interest rate $r$ but all share the same instalment size $s$.

All disbursements start the next day, on day $1 .^{14}$ Lump-sum payments are either made on Day 1, Day 3, Day 4 or Day 6. On any day that the lump sum is not paid, the participant is required to pay $s=200$ Pakistani rupees (PKR). The base lumpsum payment is either $900 \mathrm{PKR}$ (i.e. $r=-10 \%), 1,000 \mathrm{PKR}(r=0)$ or 1,100 PKR $(r=+10 \%)$. At the time of the experiment, 200 Pakistani rupees was worth approximately US $\$ 1.90 ; 1,000$ rupees was therefore approximately US $\$ 9.50 .^{15}$

The Table 1 illustrates the payment schedule for a contract with lump-sum payment on day $p=3$ and interest rate $r=+10 \%$ :

Table 1

Payment Schedule Illustration

\begin{tabular}{lccccccc}
\hline \hline & Day 0 & Day 1 & Day 2 & Day 3 & Day 4 & Day 5 & Day 6 \\
\hline $\begin{array}{l}\text { Participant pays } \\
\text { Bank pays }\end{array}$ & Take up decision & 200 & 200 & 1,100 & 200 & 200 & 200 \\
\hline \hline
\end{tabular}

\footnotetext{
13 From the point of view of the participant, the payment structure of this contract is equivalent to a oneoff random ROSCA (Kovsted and Lyk-Jensen, 1999), but it is implemented on an individual basis.

${ }^{14}$ This short delay serves to mitigate against distortions in take-up arising from differences in the credibility of lump-sum payment between contracts (Coller and Williams, 1999; Dohmen et al., 2012).

${ }_{15}$ As we explain in more detail shortly, the median household income in the study area is approximately 600 PKR per day.
} 
Since there are three possible interest rate values and four possible days for the lump-sum payment, 12 different contracts are used in the experiment to represent each combination of $p$ and $r$. At the beginning of the week on day 0 each participant receives a take-it-or-leave-it offer of one of these contracts, and must decide on the spot whether to accept it or not. We test:

(i) whether there is demand for this generalised ROSCA contract; and

(ii) if so, how demand varies with the terms of the contract.

\subsection{Experimental Implementation}

We ran this experiment over September and October 2013 in Sargodha, Pakistan Punjab. Our sample comprises female clients of the National Rural Support Programme (NRSP). At the time of running the experiment, all participants were active NRSP borrowers. ${ }^{16}$ The experiment was conducted through four NRSP offices in the Sargodha district. Female members of these four branches were invited to attend meetings set in locations near their residences. Members who stayed for the first meeting were individually offered a generalised ROSCA contract randomly selected from the 12 possible contracts described above. Participants were free to take up or reject the contract offered in that week. Even if they refused the contract offered to them in that week, participants were still required to participate in the meeting held the following week, when they were again offered a contract randomly selected from the list of 12. In total, there were three weekly meetings. Those who attended all three meetings (whether choosing to accept or reject the product for that week) received a show-up fee of 1,100 PKR at the end of the trial. Once a subject had accepted a contract, they were expected to abide by the terms of that contract. Failure to do so resulted in exclusion from the rest of the experiment - and from receiving the show-up fee. NRSP ensured that subjects did not benefit or suffer financially from dropping out (apart from losing the show-up fee). In practice, this meant reimbursing subjects for partial contributions, and recouping amount received but not fully repaid.

We implemented the experiment in NRSP branches located within a $30 \mathrm{~km}$ radius around the city of Sargodha. 32 microfinance groups participated in the experiment. In each group, the product was explained by an experienced NRSP staff member. ${ }^{17}$ In three of these groups, there were breaches of experiment protocol. ${ }^{18}$ We drop these three groups from the analysis, a decision taken before we began any of the analysis.

16 Depending on the client, NRSP loans were classified either as 'livestock', 'enterprise' or 'agricultural' loans - though the distinction is largely in name. The loan size for all three types of loan is 20,000 PKR for first-time borrowers, with increments of 5,000 per repeat loan. The duration of enterprise and livestock loans is usually 12 months; the duration of an agriculture loan varies by crop but cannot exceed 8 months.

17 These staff members received precise instructions on how to present the experimental design. In the online Appendix, we analyse take-up patterns by staff member and by location. If the results were driven by different enumerators having explained the product differently - for example, by some enumerators having confused participants about the show-up fee - then we would expect substantial clustering of take-up behaviour by staff member or by location. As the online Appendix shows, there is substantial heterogeneity in take-up patterns, both within location and for participants instructed by the same staff member.

18 These breaches were through no fault of the research team or the implementing partner, NRSP. This is discussed in more detail in the online Appendix. 
This means that we have a total of 29 microfinance groups/clusters in the following analysis. $^{19}$

In these 29 groups, we collected baseline data from 955 respondents. Of these, 889 decided to participate in the experiment and made a decision on the first offered contract. Of the 66 women who left before the experiment began, 41 stated that they did not have time to attend each day; six said that they did not understand the product. Our sample ranges in age from 18 to 70, with a median age of 38. Of the participants $(90 \%)$ are married and only $30 \%$ have completed one or more years of schooling. By design, the respondents live close to the meeting place (the median is four minutes' walking time). This is important for ensuring that take-up decisions are based primarily on the financial costs and benefits of the products offered, rather than on the time and effort of commuting to the place of payment. Detailed summary statistics are presented in the online Appendix.

Table 2 describes the main variables used in the analysis. We place particular focus on variables proxying for frequency with which participating households receive an income, such as occupation..$^{20}$ As the Table shows, the overwhelming majority of the subjects $(88 \%)$ have at least one source of income from employment other than permanent wage employment - that is, from casual labour (i.e. paid a daily wage), selfemployment in a business, or sales of dairy farm products. $^{21}$ (As a convenient shorthand, we refer to such income as 'non-salaried income'. We refer to income from permanent wage employment as 'salaried income'.) In the population at large, $42 \%$ of households have a member in permanent wage employment (PSLM, 2010-1). This proportion is smaller (28\%) among the experimental subjects, who are selected among clients of a microfinance organisation that, in part, targets self-employed individuals. Most households with permanent wage employment also have some source of daily income; $19 \%$ of all participating households have both. ${ }^{22}$

\footnotetext{
${ }^{19}$ Our results are robust to the use of Moulton-corrected standard errors. This is not surprising given that most of our results of interest are highly significant.

${ }^{20}$ Unfortunately, we were unable to collect baseline data on frequency of monetary inflows into the household. Prompted by an anonymous referee, we returned to Sargodha in mid-2016 to resurvey a sample of 100 of the original participants to the experiment and asked them about the frequency with which they receive an income. When we asked respondents directly about daily income, $58 \%$ report that either they or another household member earn income each day (95\% confidence interval: 48-67\%). A substantial number of respondents also have an occupation yielding an income or business cash flow that varies daily but does not necessarily provide them with a guaranteed daily income. These include farmers, non-farm self-employed and casual labourers. When we combine these occupations, the proportion of households with income that varies daily is $86 \%$ of the sample (95\% confidence interval: 78-92\%). (Further, of our 100 resurveyed respondents, 65 agree with the statement 'My household needs an income each day to make it to the next day'.) The resurvey confirms that there is a strong positive correlation between having daily income and having employment either as a farmer, non-farm self-employed, or casual labourer: of the 78 respondents having a family member in one of these three occupational categories, 50 report having daily income (i.e. $64 \%$ ); of the 22 respondents not having a family member in one of those occupations, only eight report receiving a daily income (i.e. $36 \%$ ).

21 Since subjects were not asked whether they derive income from the sale of dairy products, this is inferred from livestock ownership (cow or bullock). Given the widespread use of livestock as source of dairy income, this is a relatively innocuous assumption - and is the best we can do with the data at hand.

${ }^{22}$ Some $3 \%$ of participating households do not report an occupation that can be a source of earned income - they must have a source of income that enables them to pay daily instalments, but we do not know what it is.
} 
Table 2 also reports p-values for randomisation balance across each variable; this is calculated by regressing each baseline variable on the experimentally assigned interest rate and payment day, using a saturated specification. We find two of the 11 variables to be unbalanced at the $90 \%$ confidence level. We provide a more extensive set of balance tests in the online Appendix, from which we conclude that the randomisation is correctly balanced. ${ }^{23}$

Attrition from the experiment has two sources: 80 subjects defaulted on a contract, and another 98 simply stopped attending. ${ }^{24}$ The large majority of defaults and exits occur within or at the end of the first round. Most exiting subjects answered an exit questionnaire, stating the reason for leaving. Defaulting subjects list shocks (e.g. illness, travel), inability to pay and unwillingness to come to daily meetings as their main reasons for leaving. Non-defaulting leavers list unwillingness to come to daily meetings as the main reason. There is a small but significant effect of contract terms on the probability of default: women offered $p=1$ were about 2.7 percentage points less likely to default than women drawing $p=3, p=4$ or $p=6$. In subsection 4.3 and the online Appendix, we show that attrition does not affect the other results.

It is worth noting that subjects who attrite forfeit the show-up fee of 1,100 PKR. Participants should therefore refuse a contract that they do not expect to fulfil: by

Table 2

Description of Main Variables

\begin{tabular}{lcc}
\hline \hline & Mean & Balance $(p)$ \\
\hline Dummy: respondent or husband earns from casual work & 0.46 & 0.037 \\
Dummy: respondent or household owns a business & 0.34 & 0.852 \\
Dummy: respondent or family owns livestock & 0.49 & 0.025 \\
Dummy: respondent or husband earns salaried income & 0.28 & 0.170 \\
$\quad \begin{array}{l}\text { Dummy: respondent or husband earns non-salaried income } \\
\text { (casual work, self-employment or livestock) }\end{array}$ & 0.19 & 0.637 \\
Dummy: respondent or husband earns non-salaried & 0.03 & 0.112 \\
$\quad$ and salaried income & & 0.891 \\
Dummy: respondent or husband earn neither salaried & 0.69 & 0.443 \\
$\quad$ nor non-salaried income & 0.43 & 0.420 \\
Dummy: 'Whenever I have money on hand, my spouse & 0.27 & 0.357 \\
$\quad$ or other family members always end up requesting some of it' & 0.27 & 0.490 \\
Dummy: 'I find it hard to save money for the future' & & \\
Dummy: respondent would use PKR 1,000 loan for a lumpy purchase & & \\
Dummy: respondent would use PKR 1,000 loan to save/invest & & \\
\hline \hline
\end{tabular}

Notes. This Table provides basic summary statistics for the main variables used in the analysis. We have 889 baseline observations for each variable (excluding the final variable, for which we have 888). For each variable, 'Balance' reports a p-value from a joint test of the null hypothesis that the variance is balanced across the treatments.

23 The analysis in the online Appendix shows that two of the 22 variables are mismatched at the $90 \%$ confidence level: the number of years as an NRSP client; and a dummy variable for whether the respondent makes the final decision on household spending (either individually or jointly with her husband or others). As a robustness check, we re-run the main estimations with these two variables as additional controls, but results are unaffected.

${ }^{24}$ Four subjects are recorded as having defaulted in one of the rounds but have participated in the remaining rounds. 
defaulting they lose a show-up fee of 1,100 PKR compared with a maximum material gain of $100 \mathrm{PKR}$ on a contract. If they had refused the contract instead of defaulting, they would have avoided a loss $\geq 1,000 \mathrm{PKR}$. Individuals who default can thus be seen as misjudging their future ability to fulfil a commitment contract. This behaviour is akin to the type of 'naive sophisticates' studied by John (2015), namely, individuals with a mistaken anticipation about their future ability to comply with an incentivised commitment contract. ${ }^{25}$

Of the 709 respondents participating in all three experiment rounds, $92 \%$ said afterwards that they understood the product, $96 \%$ said that they were glad to have participated and $87 \%$ said that they would recommend the product to a friend. ${ }^{26} 82 \%$ said that the product helped them to commit to saving and $64 \%$ said that the product helped them to resist pressure to share money with friends and family. At baseline, we asked respondents to imagine that NRSP were to loan them 1,000 PKR and asked them an open-ended question about how they would use the money. Approximately half gave a non-committal response (e.g. domestic needs or something similar). Of those who gave a specific answer, a majority listed a lumpy expenditure, that is, an expenditure not easily made in small increments. Of the lumpy expenditures described, the most common are sewing equipment, chickens or goats and school materials (particularly school uniforms). Based on responses given to this question, we create a dummy variable equal to one if the respondent would invest or save the funds, as opposed to spending them on divisible consumption.

\section{Reduced-form Results}

We begin by reporting reduced-form results. The purpose of this approach is to reassure the reader that our main findings are immediately apparent in the data, and are not an artefact of the structural estimation.

\subsection{Stylised Facts about Take-up}

Table 3 shows average take-up across the 12 different types of contract offered. The Table brings to light the first two important stylised facts. First, overall take-up is very high (approximately $65 \%$ on average). Second, take-up varies with contractual terms respondents are more likely to take a contract when $p=1$ than when $p=6$. But the variation is not large, and certainly not nearly as stark as the variation predicted by the benchmark model with $m_{t} \geq 0$.

\footnotetext{
${ }^{25}$ A standard example of naive sophisticates concerns individuals who take a membership to a gym as a commitment to exercise but fail to use it: DellaVigna and Malmendier (2006).

${ }^{26}$ Prompted by a referee's comment, we conducted a small follow-up survey in mid-2016 with 100 of the original respondents. To test respondent understanding, we described a hypothetical rotating savings committee, then asked respondents to answer specific right-or-wrong questions. Of the 100 respondents who answered the question about the pot size, 80 answered correctly without assistance. We asked about the duration of the hypothetical product; 86 correctly answered without assistance. Finally, we asked about the lottery concept as applied to the committee; 72 correctly answered without assistance. On the whole, 61 answered all three questions correctly without any assistance and 86 were able to answer all three questions correctly with minimal prompting.
} 
Table 3

Product Take-up by Contract Type

\begin{tabular}{|c|c|c|c|}
\hline \multirow[b]{2}{*}{ Payment day } & \multicolumn{3}{|c|}{ Interest rate } \\
\hline & $r=-0.1$ & $r=0$ & $r=0.1$ \\
\hline$p=1$ & $60.0 \%$ of 215 offers & $78.2 \%$ of 239 offers & $86.6 \%$ of 262 offers \\
\hline$p=3$ & $51.9 \%$ of 131 offers & $64.6 \%$ of 127 offers & $68.4 \%$ of 133 offers \\
\hline$p=4$ & $52.6 \%$ of 116 offers & $61.9 \%$ of 113 offers & $72.7 \%$ of 154 offers \\
\hline$p=6$ & $47.8 \%$ of 207 offers & $57.2 \%$ of 187 offers & $64.2 \%$ of 243 offers \\
\hline
\end{tabular}

Note. This Table shows average take-up across the 12 different types of contract offered.

Table 4 shows an important third stylised fact: there appears to be important heterogeneity across individuals. Of the 709 individuals completing all three experiment waves, $319(45 \%)$ accepted all three contracts offered, and $121(17 \%)$ accepted none of the contracts offered. This was despite the vast majority of respondents having been offered three different contracts.

The implication of this is clear, and is a fourth stylised fact: many individuals accepted both a credit contract and a savings contract, even over the very short duration of the experiment. As Table 5 shows, of the 709 respondents completing all

Table 4

Individual Heterogeneity

\begin{tabular}{lcccc}
\hline \hline & \multicolumn{3}{c}{ Unique contracts offered } & \\
\cline { 2 - 4 } Acceptances & 3 & 2 & 1 & Total \\
\hline 0 & 94 & 26 & 1 & $121(17 \%)$ \\
1 & 88 & 17 & 1 & $106(15 \%)$ \\
2 & 135 & 24 & 4 & $163(23 \%)$ \\
3 & 241 & 73 & 5 & $319(45 \%)$ \\
& 558 & 140 & 11 & $709(100 \%)$ \\
\hline \hline
\end{tabular}

Notes. This Table shows the total number of contract acceptances by individual respondents, against the total number of different types of contract offered to those individuals. It highlights that almost half the respondents accepted all contracts offered.

Table 5

Acceptance of Both Credit and Savings Contracts

\begin{tabular}{llrr}
\hline \hline & \multicolumn{2}{c}{ Accepted a savings contract? } \\
\cline { 2 - 4 } Accepted a credit contract? & No & Yes & Total \\
\hline No & 45 & 19 & 64 \\
Yes & 65 & 148 & 213 \\
Total & 110 & 167 & 277 \\
\hline \hline
\end{tabular}

Notes. This Table shows the number of respondents accepting a savings contract and the number of respondents accepting a credit contract. As a cross-tabulation, it highlights that 277 respondents were offered both a savings and a credit contract, of which 148 accepted at least one contract of each type.

(C) 2017 Royal Economic Society. 
waves, 277 were offered both a savings contract $(p=6)$ and a credit contract $(p=1)$. Of these, 148 accepted at least one savings contract and at least one credit contract.

This fact already challenges the benchmark model. Recall Prediction 5 of that model: the same individual will not demand both a savings contract with $r>0$ and a credit contract with $r \leq 0$. Table 6 considers those respondents who were both offered a savings contract with $r>0$ and a credit contract with $r \leq 0$. There were 87 such respondents; of these, $44(51 \%)$ accepted both a savings contract with $r>0$ and a credit contract with $r \leq 0$.

Similarly, the benchmark model predicts that individuals always refuse savings contracts $(p=T)$ with $r<0$ and always accept credit contracts $(p=1)$ with $r>0$. In the experiment, 184 respondents were offered at least one savings contract with $r<0$; of these 86 accepted at least one $(47 \%) .{ }^{27}$ Two hundred and thirty respondents were offered at least one credit contract with $r>0$; of these, 29 rejected at least one $(13 \%)$.

Together, these stylised facts suggest that many of the microfinance clients view saving and borrowing contracts as substitutes. Indeed, as Table 7 summarises, the experiment provided 439 of our 709 respondents an opportunity to violate at least one of the specific predictions of the benchmark model: 155 of them did so.

Table 6

Acceptance of Savings Contracts with $r \geq 0$ and Credit Contracts with $r \leq 0$

\begin{tabular}{|c|c|c|c|}
\hline \multirow{2}{*}{$\begin{array}{l}\text { Accepted a credit } \\
\text { contract with } r \leq 0 \text { ? }\end{array}$} & \multicolumn{2}{|c|}{$\begin{array}{c}\text { Accepted a savings contract } \\
\text { with } r>0 \text { ? }\end{array}$} & \multirow[b]{2}{*}{ Total } \\
\hline & No & Yes & \\
\hline No & 15 & 11 & 26 \\
\hline Yes & 17 & 44 & 61 \\
\hline Total & 32 & 55 & 87 \\
\hline
\end{tabular}

Notes. This Table is motivated by Prediction 5 of the benchmark model. It shows that 87 respondents were offered a savings contract with $r>0$ and a credit contract with $r \leq 0$; of these 44, accepted at least one contract of each type.

Table 7

Violations of the Benchmark Model

\begin{tabular}{lcr}
\hline \hline Prediction & $\begin{array}{c}\text { Opportunity to } \\
\text { violate prediction }\end{array}$ & $\begin{array}{c}\text { Prediction } \\
\text { violated }\end{array}$ \\
\hline Will not accept savings with $r>0$ and credit with $r \leq 0$ & 87 & $44(51 \%)$ \\
Always refuse savings with $r<0$ & 184 & $86(47 \%)$ \\
Always accept credit with $r>0$ & 230 & $29(13 \%)$ \\
Any prediction & 439 & $155(35 \%)$ \\
\hline \hline
\end{tabular}

Note. This Table summarises the predictions of the benchmark model; it shows the number of respondents violating such predictions, compared to the number being offered the opportunity to do so.

27 Of these 86, 84 accepted all such contracts that they were offered: 163 respondents were offered one such contract, of whom 72 accepted it; 19 were offered two such contracts, of whom 11 accepted both; and two were offered three such contracts, of whom one accepted all three.

(C) 2017 Royal Economic Society. 


\subsection{Product Take-up, Income Frequency, and Commitment Needs}

We use regression analysis to summarise in a compact way how the take-up response of experimental subjects varies with contract terms. We begin by documenting the sensitivity of take-up to the interest rate and the timing of the lump-sum payment. Formally, let $y_{i w}$ be a dummy variable for whether individual $i$ agreed to the offered contract in experiment wave $w \in\{1,2,3\}$. Define rneg $_{i w}$ as a dummy for $r_{i w}=-0.1$ and rpos $_{i w}$ as a dummy for $r_{i w}=0.1$ (with zero interest as the omitted category). Further let $p 1_{i w}$ and $p 6_{i w}$ be dummy variables for time of payment (leaving days 3 and 4 as the joint omitted category). We test sensitivity to contract terms by estimating a linear probability model of the form:

$$
y_{i w}=\beta_{0}+\beta_{1} \times \operatorname{rneg}_{i w}+\beta_{2} \times \operatorname{rpos}_{i w}+\beta_{3} \times p 1_{i w}+\beta_{4} \times p 6_{i w}+\mu_{i w} .
$$

Standard errors are clustered by microfinance group. ${ }^{28}$

We estimate this regression for the entire sample. We then examine variation in takeup associated with differences in the frequency of income flows and in the commitment needs of the household. We start by investigating whether take-up varies with various proxies for the commitment needs of the household. The results are presented in Table 8. We find that take-up is higher among households that face many financial requests from family members and among households that find it easier to save. The latter result seems at first glance to contradict our model but, given the context of the experiment, participants who state it is difficult for them to save may include many who are too poor to save. We also find that respondents who stated that they would save or invest a hypothetical loan have a significantly and substantially larger intercept term than those who did not, and are significantly less responsive to contractual terms (in particular, less responsive to being offered a positive interest rate and to having payment on day 1). Similarly, respondents who report pressure from family and friends are significantly less responsive to contractual terms - again, less responsive to being offered a positive interest rate and to having payment on day 1 . We interpret these results as consistent with the idea that these respondents value the product-whether offered in the credit or the savings domain - as a means to accumulate a lump-sum. ${ }^{29}$

Next, we consider variation in income frequency. ${ }^{30}$ As discussed in the conceptual section, we expect demand for a financial product with daily deposits to be highest among households that have daily income flows. It is also possible that households in permanent wage employment have less demand for a lump sum because they can finance lumpy expenditures from salaries paid at regular weekly or monthly intervals. If this is true, such households should be primarily interested in contracts that generate a positive return (i.e. $r=0.1$ ). To investigate these issues, we split households into four

${ }^{28}$ In the online Appendix, we present a battery of alternative regression models - including a saturated model - specified in the pre-analysis plan. All our conclusions are robust to using these alternative specifications instead of the simpler specification presented here.

${ }^{29}$ We cannot entirely rule out that some respondents took up the product purely as a commitment device to work harder each day. This could apply, for instance, to the New York taxi drivers of Camerer et al. (1997, p. 407), who 'set a loose daily income target and quit working once they reach that target', or to alcoholic rickshaw drivers as in Schilbach (2017). Given that all our respondents are women and not all of them work, we find it unlikely in this context that the product is serving to commit respondents to worker harder.

${ }^{30}$ The online Appendix discusses subgroup variation in further detail, and shows regression results for all subgroups, including all subgroups that were listed in the pre-analysis plan. 
THE ECONOMIC JOURNAL

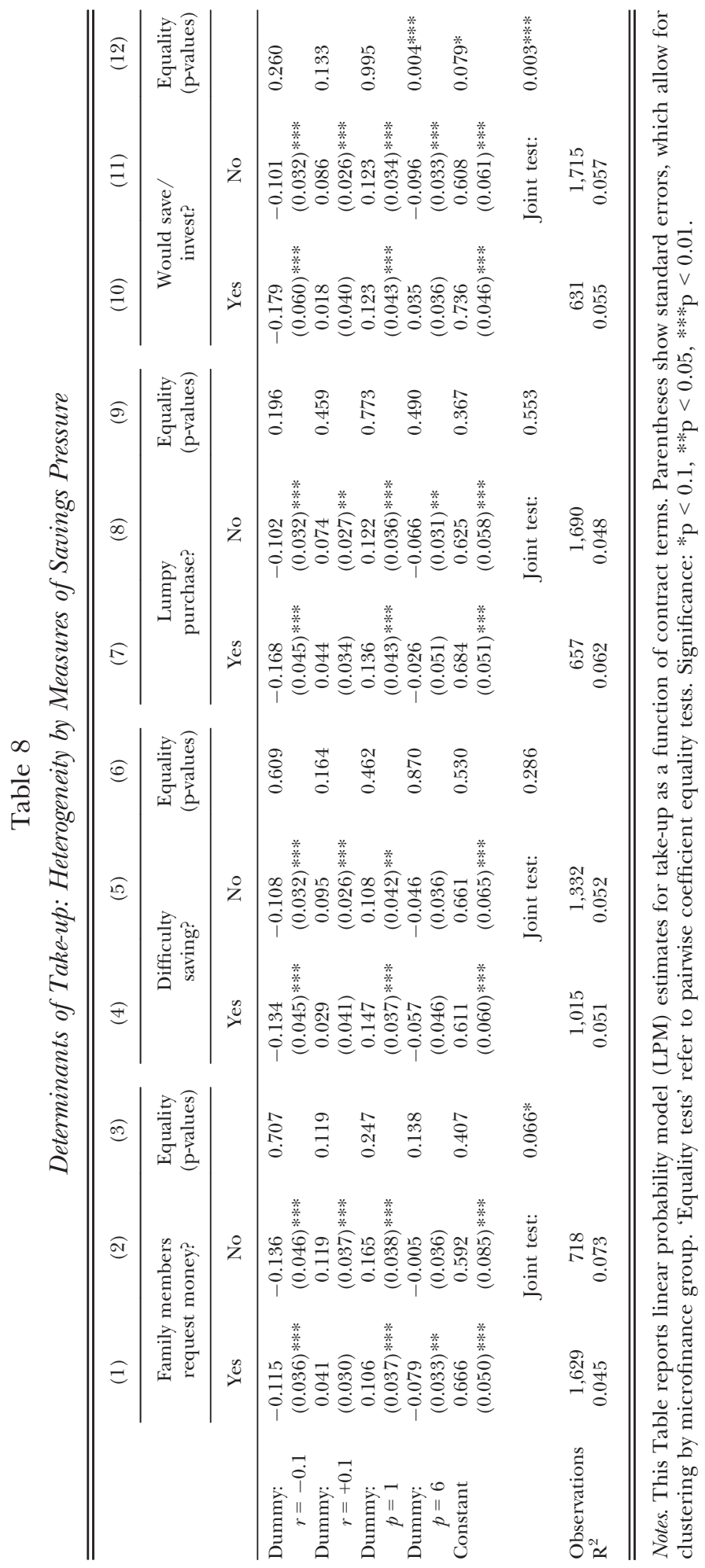


Table 9

Determinants of Take-up: Heterogeneity by Baseline Income Flow

\begin{tabular}{|c|c|c|c|c|c|c|}
\hline & (1) & (2) & (3) & (4) & (5) & (6) \\
\hline $\begin{array}{l}\text { Salaried income? } \\
\text { Non-salaried income? }\end{array}$ & $\begin{array}{l}\text { (Whole sample) } \\
\text { (Whole sample) }\end{array}$ & $\begin{array}{l}\text { No } \\
\text { No }\end{array}$ & $\begin{array}{l}\text { Yes } \\
\text { No }\end{array}$ & $\begin{array}{l}\text { No } \\
\text { Yes }\end{array}$ & $\begin{array}{l}\text { Yes } \\
\text { Yes }\end{array}$ & $\begin{array}{c}\text { Equality } \\
\text { tests } \\
\text { (p-values) }\end{array}$ \\
\hline Dummy: $r=-0.1$ & $\begin{array}{l}-0.120 \\
(0.029) * * *\end{array}$ & $\begin{array}{r}-0.017 \\
(0.131)\end{array}$ & $\begin{array}{c}-0.123 \\
(0.086)\end{array}$ & $\begin{array}{l}-0.112 \\
(0.030) * * *\end{array}$ & $\begin{array}{l}-0.180 \\
(0.052) * * *\end{array}$ & 0.657 \\
\hline Dummy: $r=+0.1$ & $\begin{array}{l}0.066 \\
(0.023) * * *\end{array}$ & $\begin{array}{c}0.133 \\
(0.124)\end{array}$ & $\begin{array}{c}0.136 \\
(0.077)^{*}\end{array}$ & $\begin{array}{l}0.068 \\
(0.028) * *\end{array}$ & $\begin{array}{c}0.022 \\
(0.051)\end{array}$ & 0.480 \\
\hline Dummy: $p=1$ & $\begin{array}{l}0.125 \\
(0.031) * * *\end{array}$ & $\begin{array}{l}0.258 \\
(0.126) * *\end{array}$ & $\begin{array}{l}0.283 \\
(0.083) * * *\end{array}$ & $\begin{array}{l}0.105 \\
(0.028) * * *\end{array}$ & $\begin{array}{l}0.096 \\
(0.051) *\end{array}$ & 0.155 \\
\hline Dummy: $p=6$ & $\begin{array}{l}-0.055 \\
(0.027) *\end{array}$ & $\begin{array}{c}0.038 \\
(0.129)\end{array}$ & $\begin{array}{r}-0.090 \\
(0.075)\end{array}$ & $\begin{array}{l}-0.054 \\
(0.029) *\end{array}$ & $\begin{array}{r}-0.060 \\
(0.052)\end{array}$ & 0.881 \\
\hline Constant & $\begin{array}{l}0.641 \\
(0.049) * * *\end{array}$ & $\begin{array}{l}0.548 \\
(0.112) * * *\end{array}$ & $\begin{array}{l}0.559 \\
(0.073) * * *\end{array}$ & $\begin{array}{r}0.630 \\
(0.026) * * * \\
\text { Joint test of } \\
\text { paramet }\end{array}$ & $\begin{array}{l}0.744 \\
(0.049) * * * \\
\text { all }\end{array}$ & $\begin{array}{l}0.098 * \\
0.000 * * *\end{array}$ \\
\hline $\begin{array}{l}\text { Observations } \\
\mathrm{R}^{2}\end{array}$ & $\begin{array}{l}2,347 \\
0.051\end{array}$ & $\begin{array}{r}77 \\
0.081\end{array}$ & $\begin{array}{r}203 \\
0.127\end{array}$ & $\begin{array}{l}1,616 \\
0.042\end{array}$ & $\begin{array}{r}451 \\
0.065\end{array}$ & \\
\hline
\end{tabular}

Notes. This Table reports LPM estimates for take-up as a function of contract terms. Parentheses show standard errors, which allow for clustering by microfinance group. 'Equality tests' refer to coefficient equality across columns (2), (3), (4) and (5). Significance: $* \mathrm{p}<0.1, * * \mathrm{p}<0.05$, ***p $<0.01$.

categories according to whether or not they have salaried income, and whether or not they have non-salaried income. As discussed earlier, in the study area non-salaried income implies high-frequency - e.g. daily - inflows of income. We estimate (4) separately for each group. Results are presented in Table 9.

We see that households with non-salaried income have a higher intercept and thus higher take-up in general, in agreement with predictions. Households without nonsalaried income seem to be more sensitive to $r>0$ and to $p=1$, suggesting that their takeup is more motivated by standard motives (e.g. profitability and impatience) than by demand for commitment saving. Take-up is highest among households with both salaried and non-salaried forms of income. One possible explanation is that these households are richer and more financially secure and thus have higher demand for credit and savings instruments, which they can finance from high-frequency non-salaried income.

\subsection{Extensions and Robustness}

We now investigate the robustness of our results. First, we test for the effect of lagged take-up (which we instrument using the lagged contractual offer). We find that lagged take-up has a large and highly significant effect: accepting the contract offer in period $t$ causes a respondent to be about 30 percentage points more likely to accept in period $t+1$. This speaks to a possible 'familiarity' or 'reassurance' effect, whereby trying the product improves respondents' future perceptions of the offer. The online Appendix also reports a test of parameter stability across experiment waves. We find a large and significant decline in willingness to adopt in the third experimental round. 
In addition, we observe a significant increase in the sensitivity to a positive interest rate, and to a negative interest rate when $p=1$. This could be due to a variety of causes, including respondent fatigue. The online Appendix reports a reduced form regression of take-up on past contractual terms. We find that a negative interest in the previous round decreases take-up in the current period. This result disappears in the saturated model. These findings do not affect the main results of interest.

We run several other robustness checks. The online Appendix reports a battery of estimations on attrition. We find that respondents are more likely to attrite after having been offered a contract with payment on day 6 (regardless of whether the interest rate was positive, negative or zero). We find no other significant effect of contractual terms on attrition. A separate estimation (omitted for brevity) tests attrition on a large number of baseline characteristics; none of the characteristics significantly predicts attrition. Further, the online Appendix compares estimation results with only those respondents who remained in the experiment for all three rounds. We find that this has no significant effect on the parameter estimates $(p=0.334) .{ }^{31}$ We also test for parameter stability when attrition is taken to be an indication of refusal of the product. In the online Appendix we show that parameter estimates are not significantly affected when attrition is taken to imply refusal.

\section{Structural Analysis}

Regression results shown so far indicate:

(i) a high take-up in general;

(ii) a small but statistically significant sensitivity to the terms of the contract; and

(iii) some treatment heterogeneity on income frequency and on baseline observable characteristics - particularly on whether respondents would save/invest a hypothetical loan, and whether respondents report pressure from friends or family to share cash on hand.

These regression results document the general pattern of take-up but they do not identify the kind of model heterogeneity that can account for this pattern. Put differently, the regressions identify average treatment effects - but they do not identify the underlying distribution of behavioural types among participants. Yet this underlying distribution is a critical object of interest for the study: we want to know what proportion of participants behave as the benchmark model predicts, what proportion follow the alternative model presented in the conceptual section and what proportion follow neither of the two.

To recover that underlying distribution, we use a discrete finite mixture model. This model exploits the panel dimension of the data to estimate the distribution of underlying behavioural types in the sample. To endow those behavioural types with economic meaning, we use a structural framework. In this Section, we parameterise the model

\footnotetext{
31 We have also confirmed that the results are not driven by a 'day of week' effect. We have further re-run the estimations including the two covariates for which the randomisation was unbalanced (namely, years as a microfinance client, and whether the respondent makes the final decision on spending). Our conclusions are robust to the inclusion of these additional controls.
} 
developed in Section 1 and use numerical methods to obtain predictions about the takeup behaviour of different types of decision-makers. The results show that approximately $75 \%$ of participants can have their decisions rationalised by at least one of the scenarios considered by the model; of these scenarios, the largest share comprises respondents who value lump-sum payments and who struggle to hold cash over time. ${ }^{32}$

\subsection{A Structural Model}

We begin by parameterising the conceptual framework of Section 1. First, we model respondents as having $\log$ utility in consumption $c$, and receiving an additively separable utility gain from consuming the lumpy good: $u(c, L ; \gamma)=\ln c+\gamma \times L$, where $L \in\{0,1\}$. The parameter $\gamma$ is at the heart of the structural estimation. If $\gamma=0$, respondents behave as if they have no preference for lumpy consumption; as $\gamma$ increases, the importance of lumpy consumption increases relative to continuous consumption $c$ - and demand for lump-sum accumulation goes up. ${ }^{33}$

To give a meaningful interpretation to the magnitudes of $c$ and $\gamma$, we need a normalisation for income as anchor. We use $y_{i w}=599$ PKR. This is the median daily household income across the district of Sargodha from the 2010-1 PSLM survey (corrected for CPI inflation since 2011). We set $\alpha=(T-1) \times s \times(1-0.1)=900$, as a description of the kind of lumpy expenditure made possible by the contracts we offered. For simplicity - and given the short time-frame of the experiment - we assume that the discount factor $\beta=1 .^{34}$

We solve the problem numerically by a series of nested optimisations. ${ }^{35}$ Table 10 shows the take-up predictions coming out of the model for different parameter values. There is a close congruence with theoretical predictions made in Section 1. This is hardly surprising given that the structural specification is a parameterised version of the models presented in that Section. In particular, Types A, B and C reflect the benchmark model. Thus, for example, as predicted in Section 1, these types always accept credit contracts $(p=1)$ with $r>0$, and never demand both a savings contract with $r>0$ and a credit contract with $r \leq 0$; indeed, in the structural implementation, the benchmark model predicts take-up only for $r>0$. Types D, E, F and G reflect the alternative model. As in earlier predictions, time of payment is irrelevant and the behaviour of these types differ only in their sensitivity to $r$, this heterogeneity is driven

${ }^{32}$ In the original pre-analysis plan, we had specified a simpler structural model that we intended to estimate. We have abandoned that model in favour of the current model. Results from that model add nothing of substance to the current structural results.

The assumption of log utility could readily be changed - for example, by using a CRRA utility. However, the curvature of that function (i.e. reflecting the intertemporal elasticity of substitution) is not separately identified since there is nothing in the experimental design to shed light on individuals' intertemporal substitution preferences. We therefore use $\log$ utility for convenience. We could vary this assumption, but doing so would not change any of the predictions of the model, and would therefore not change any of the conclusions from the structural estimation. It would, of course, require a reparameterisation of the critical values of $\gamma$ in Table 9 - but these values serve simply as an expositional device to capture demand for lumpsum accumulation.

34 This assumption, too, could be changed by setting another value for $\beta$. Since the experiment is not designed to identify intertemporal preferences, it is convenient to set $\beta=1$ given that the time horizon of the experiment is very short (i.e. 6 days) and that present bias is deliberately mitigated by separating take-up decisions taken on day 0 from any of the payments that take place on days 1 to 6 .

35 The algorithm is discussed in detail in the online Appendix. 
Table 10

Definition of Possible Respondent Types

\begin{tabular}{|c|c|c|c|c|c|c|c|c|c|c|c|c|c|}
\hline & \multirow{3}{*}{$\frac{r}{p}$} & \multicolumn{12}{|c|}{ Contract offered } \\
\hline & & \multicolumn{4}{|c|}{-0.1} & \multicolumn{4}{|c|}{0} & \multicolumn{4}{|c|}{0.1} \\
\hline & & 1 & 3 & 4 & 6 & 1 & 3 & 4 & 6 & 1 & 3 & 4 & \\
\hline Type & Definition & \multicolumn{12}{|c|}{ Decision $(1=$ accept $)$} \\
\hline \multicolumn{14}{|c|}{ Benchmark model } \\
\hline A & $m_{t} \geq 0$ and $\gamma_{e v} \in[-900,1,320)$ & 0 & 0 & 0 & 0 & 0 & 0 & 0 & 0 & 1 & 0 & 0 & \\
\hline B & $m_{t} \geq 0$ and $\gamma_{e v} \in[1,320,1,410)$ & 0 & 0 & 0 & 0 & 0 & 0 & 0 & 0 & 1 & 1 & 0 & \\
\hline $\mathrm{C}$ & $m_{t} \geq 0$ and $\gamma_{e v} \geq 1,410$ & 0 & 0 & 0 & 0 & 0 & 0 & 0 & 0 & 1 & 1 & 1 & \\
\hline \multicolumn{14}{|c|}{ Alternative model } \\
\hline $\mathrm{D}$ & $m_{t}=0$ and $\gamma_{e v} \in[-900,1,950)$ & 0 & 0 & 0 & 0 & 0 & 0 & 0 & 0 & 0 & 0 & 0 & \\
\hline $\mathrm{E}$ & $m_{t}=0$ and $\gamma_{e v} \in[1,950,2,430)$ & 0 & 0 & 0 & 0 & 0 & 0 & 0 & 0 & 1 & 1 & 1 & \\
\hline $\mathrm{F}$ & $m_{t}=0$ and $\gamma_{e v} \in[2,430,3,110)$ & 0 & 0 & 0 & 0 & 1 & 1 & 1 & 1 & 1 & 1 & 1 & \\
\hline G & $m_{t}=0$ and $\gamma_{e v} \geq 3,110$ & 1 & 1 & 1 & 1 & 1 & 1 & 1 & 1 & 1 & 1 & 1 & \\
\hline
\end{tabular}

Notes. This Table records the predictions of the structural model for different types of contract offered. As a benchmark, we normalise daily income to 599 PKR: the median daily household income for the district of Sargodha from the PSLM 2010-1 survey (corrected for CPI inflation).

by variation in the demand for lump-sum accumulation. To illustrate the magnitude of the estimates of $\gamma$ better, we present a stylised measure of equivalent variation, $\gamma_{e v}$. This is defined through a simple thought experiment. Imagine, in a static setting, a respondent holding a daily income $y$. Imagine her facing a cost of lumpy consumption $\alpha$, and allow her to spend $y$ either on purchasing the lumpy consumption good $L$ or on divisible consumption $c$. We define $\gamma_{e v}$ as the additional money transfer required to persuade her not to consume the lumpy good - that is, $\ln (y)+\gamma \equiv \ln \left(y+\alpha+\gamma_{\text {ev }}\right)$.

The structural model is necessarily stylised. ${ }^{36}$ We therefore do not ask the reader to interpret Table 9 literally. Rather, the purpose of the Table is to identify stylised predictions about the different patterns of adoption that we might expect to observe, each of which is grounded in explicit behavioural assumptions. We interpret the results of the mixture model in light of their structural underpinning. But they remain informative about take-up patterns even if we dismiss their structural interpretation.

\subsection{A Discrete Finite Mixture Estimator}

We want to estimate the structural model with maximal heterogeneity, i.e. we want to allow different respondents to have different values of $\gamma$ and to differ in whether they are constrained to $m_{t}=0$ or not. To do this, we use a discrete finite mixture model. This

\footnotetext{
${ }^{36}$ For instance, it implies that respondents demand credit under $r=-0.1$ only if they are unable to hold cash balances between periods (i.e. if they are Type F or G). Take up of such a credit contract could also arise because the respondent has access to an investment opportunity that yields a return in excess of $10 \%$ over a six day period. While we cannot rule out that such cases exist, we deem them highly unlikely in the context of the study. Conversely, a respondent in the benchmark model may decline a contract with $p=1, r=0.1$ if the transaction cost of paying the daily instalments is large enough. Although we cannot rule out this possibility entirely, we suspect that, since participation in the experiment is voluntary, such individuals are not in the study.
} 
follows a body of recent literature - led by Glenn Harrison, Elisabet Rutström and coauthors - showing how laboratory behaviour can be analysed empirically by allowing for a mixture of different behaviour types in a population: Andersen et al. (2008, 2014); Harrison and Rutström (2009); Harrison, Humphrey, and Verschoor (2010); Harrison, Lau, and Rutström (2010); Coller, Harrison, and Rutström (2012). Our specific approach is similar in spirit to Stahl and Wilson (1995): the model identifies a number of different types of respondents, and we estimate the proportion of each type in the population. ${ }^{37}$ Mixture models for experimental analysis often require the estimation of both mixing proportions and other parameters - e.g. parameters characterising the shape of participants' utility functions. In our context, Table 10 makes joint discrete predictions. Hence, in contrast to previous papers, we develop a simple non-parametric maximum likelihood estimator to recover the mixture distribution.

We take the predictions in Table 10 as the foundation for estimation. We define this model over combinations of the contracts offered in the first, second, and third waves. We index all contract offer combinations by $k \in\{1, \ldots, K\}$, where $K$ is the total number of contract combinations possible. ${ }^{38}$ For each contract combination, a respondent can make eight possible choices for $\left(y_{i 1}, y_{i 2}, y_{i 3}\right)$. We index these eight possible choices by $c \in\{1, \ldots, C\}$.

Table 10 shows that the model implies seven distinct types; we index these types as $t \in\{1, \ldots, T\}$. Define a matrix $\boldsymbol{X}$ of dimensions $(K C) \times T$, such that element $\boldsymbol{X}_{C \times(k-1)+c, t}$ records the probability that type $t$ will make choice $c$ when faced with contract combination $k$. To illustrate, consider 'Type A' from Table 10. Suppose that someone of this type is offered the following three contracts: $(r, p)=(0.1,1)$, then $(r, p)=(0,3)$, then $(r, p)=(-0.1,4)$. Table 10 shows that this person should accept the first of these, but not the second or third; thus, with probability 1 , someone of Type A should respond to this contract combination by choosing $(1,0,0)$.

Define a $(K C)$-dimensional vector $y$, such that element $y_{C \times(k-1)+c}$ is the sample probability of a respondent choosing choice combination $c$, conditional on having been offered contract combination $k$. Define $\boldsymbol{\beta}$ as a $T$-dimensional vector for the proportions of each type in the population ( $\operatorname{such}$ that $\sum_{t} \boldsymbol{\beta}_{t}=1$ ). Then, straightforwardly, $\boldsymbol{y}=\boldsymbol{X} \boldsymbol{\beta}$. $\boldsymbol{\beta}$ is the key structural parameter of interest. By standard properties of the Moore-Penrose pseudoinverse, $\boldsymbol{\beta}$ is identified if and only if $\operatorname{rank}(\boldsymbol{X})=T$. (In the current application, $r a n k$ $(\boldsymbol{X})=T=7 ; \boldsymbol{\beta}$ is therefore identified.) Given that $\boldsymbol{\beta}$ is identified, we can estimate efficiently by non-parametric maximum likelihood. Let the sample size be $N$, and let the number facing contract combination $k$ be $n_{k}$. Then the log-likelihood for the sample is:

$$
\ell(\boldsymbol{\beta})=\sum_{k=1}^{K} n_{k} \times \sum_{c=1}^{C} \boldsymbol{y}_{[C \times(k-1)+c]} \times \ln \left(\sum_{t=1}^{T} \boldsymbol{\beta}_{t} \times \boldsymbol{x}_{[C \times(k-1)+c], t}\right) .
$$

\footnotetext{
37 Von Gaudecker et al. (2011, p. 677) use an alternative approach with a continuous distribution of the parameters of interest, on the basis that 'finite mixture models have difficulty handling a large number of potential values for the parameters and a small set of values seems insufficient to explain the very heterogeneous choice behaviour illustrated'. The finite mixture model is appropriate for our case, however, given that the model only predicts a relatively small number of distinct forms of behaviour (namely, the behaviour shown in the rows of Table 10).

38 There are $12^{3}=1,728$ possible contract combinations that could have been offered; in practice, only 554 of these possible combinations were actually offered.
} 


\subsection{Structural Results}

The structural estimates are reported in Table 11 . The Table includes $95 \%$ confidence intervals calculated using a bootstrap with 1,000 replications. The results are stark: we estimate that about $65 \%$ of respondents find it difficult to hold onto cash from day to day (Types D, E, F and G). For about $55 \%$ of respondents (i.e. Types $\mathrm{G}$ and H), this is coupled with a large value of lump-sum accumulation (in the sense of $\gamma_{e v}>1,950 \mathrm{PKR}$ ). These proportions dwarf those of respondents who adhere to the benchmark model in which $m_{t} \geq 0$ (Types A, B and C): the combined proportion of these respondents in the study sample is only about $10 \%$.

In Table 12, we estimate the mixture model separately for different subsets. Mirroring Table 7, we disaggregate by:

(i) whether the respondent faces pressure from family members to share available funds;

(ii) whether the respondent reports difficulty in saving;

(iii) whether the respondent describes a lumpy purchase at baseline; and

(iv) whether the respondent indicates a desire to save/invest a hypothetical loan of 1,000 PKR.

The last panel of the Table reports likelihood ratio tests to compare estimates between columns. ${ }^{39}$

Table 11

Structural Estimates

\begin{tabular}{lccc}
\hline \hline & & \multicolumn{2}{c}{$95 \%$ confidence } \\
\cline { 3 - 4 } Type & Estimated proportion & Lower & Upper \\
\hline Type A & $10.1 \%$ & $10.0 \%$ & $14.7 \%$ \\
Type B & $13.6 \%$ & $10.0 \%$ & $15.9 \%$ \\
Type C & $15.0 \%$ & $11.8 \%$ & $18.4 \%$ \\
Type D & $11.7 \%$ & $17.9 \%$ & $14.5 \%$ \\
Type E & $13.2 \%$ & $11.0 \%$ & $15.8 \%$ \\
Type F & $11.7 \%$ & $3.4 \%$ & $14.9 \%$ \\
Type G & $40.5 \%$ & $21.0 \%$ & $44.5 \%$ \\
Not rationalised & $24.1 \%$ & & $27.4 \%$ \\
$N$ & 709 & & \\
Log-likelihood & -529.291 & & \\
\hline \hline
\end{tabular}

Notes. This Table reports non-parametric maximum likelihood estimates from the mixture model. 'Types' refer to Table 10. 'Not rationalised' means that an individual did not behave as any of the types predict. $95 \%$ confidence intervals are obtained from a bootstrap with 1,000 replications.

${ }^{39}$ We report three tests:

(i) an omnibus test of whether the proportions in each type differ, conditional on being rationalised;

(ii) a test of whether the combined proportion in types A, B and C differs, conditional on being rationalised; and

(iii) a test of whether the proportion rationalised is equal. 
Table 12

Structural Estimates: Disaggregating by Baseline Characteristics

\begin{tabular}{|c|c|c|c|c|c|c|c|c|}
\hline & \multicolumn{8}{|c|}{ Estimated proportions } \\
\hline & \multicolumn{2}{|c|}{$\begin{array}{l}\text { Family members } \\
\text { request money? }\end{array}$} & \multicolumn{2}{|c|}{ Difficulty saving? } & \multicolumn{2}{|c|}{ Lumpy purchase? } & \multicolumn{2}{|c|}{ Would save/invest? } \\
\hline & Yes & No & Yes & No & Yes & No & Yes & No \\
\hline Type A & $0.0 \%$ & $5.1 \%$ & $0.0 \%$ & $0.2 \%$ & $3.9 \%$ & $0.0 \%$ & $1.4 \%$ & $0.8 \%$ \\
\hline Type B & $4.2 \%$ & $0.0 \%$ & $3.8 \%$ & $3.6 \%$ & $0.0 \%$ & $4.2 \%$ & $5.4 \%$ & $2.1 \%$ \\
\hline Type C & $4.9 \%$ & $5.5 \%$ & $3.4 \%$ & $5.8 \%$ & $6.0 \%$ & $4.7 \%$ & $4.3 \%$ & $5.8 \%$ \\
\hline Type D & $11.4 \%$ & $9.4 \%$ & $15.6 \%$ & $9.0 \%$ & $8.7 \%$ & $12.6 \%$ & $2.8 \%$ & $14.5 \%$ \\
\hline Type E & $1.0 \%$ & $8.5 \%$ & $3.7 \%$ & $3.2 \%$ & $0.0 \%$ & $3.9 \%$ & $0.0 \%$ & $4.1 \%$ \\
\hline Type F & $11.4 \%$ & $12.7 \%$ & $8.7 \%$ & $13.6 \%$ & $14.3 \%$ & $10.9 \%$ & $13.5 \%$ & $11.1 \%$ \\
\hline Type $\mathrm{G}$ & $40.9 \%$ & $39.3 \%$ & $36.5 \%$ & $43.6 \%$ & $42.8 \%$ & $39.5 \%$ & $47.0 \%$ & $38.1 \%$ \\
\hline Not rationalised & $26.1 \%$ & $19.5 \%$ & $28.3 \%$ & $20.9 \%$ & $24.2 \%$ & $24.1 \%$ & $25.7 \%$ & $23.6 \%$ \\
\hline$N$ & 494 & 215 & 307 & 402 & 198 & 511 & 189 & 522 \\
\hline Log-likelihood & -351.3 & -172.4 & -213.2 & -312.0 & -136.8 & -389.6 & -112.9 & -406.6 \\
\hline \multicolumn{9}{|c|}{ Hypothesis tests of equality between columns ( $p$-values): } \\
\hline All parameters: & \multicolumn{2}{|c|}{$0.080 *$} & \multicolumn{2}{|c|}{0.230} & \multicolumn{2}{|l|}{0.442} & \multicolumn{2}{|c|}{$0.003 * * *$} \\
\hline $\begin{array}{l}\text { Proportion } \\
\text { in A, B or C: }\end{array}$ & \multicolumn{2}{|l|}{0.742} & \multicolumn{2}{|l|}{0.550} & \multicolumn{2}{|l|}{0.769} & \multicolumn{2}{|l|}{0.551} \\
\hline $\begin{array}{l}\text { Proportion } \\
\text { rationalised: }\end{array}$ & \multicolumn{2}{|l|}{$0.056^{*}$} & \multicolumn{2}{|c|}{$0.022 * *$} & \multicolumn{2}{|l|}{0.962} & \multicolumn{2}{|l|}{0.565} \\
\hline
\end{tabular}

Notes. This Table reports non-parametric maximum likelihood estimates from the mixture model, disaggregated by binary baseline covariates. 'Types' refer to Table 10. 'Not rationalised' means that an individual did not behave as any of the types predict. The last panel of the Table reports likelihood ratio tests to compare estimates between columns. 'All parameters' refers to tests of whether the proportion of each type are common between columns $(\mathrm{df}=6)$. 'Proportion in $\mathrm{A}, \mathrm{B}$ or $\mathrm{C}$ ' tests whether the proportion adhering to the benchmark model is equal across columns $(\mathrm{df}=1)$. Note that this is equivalent to testing whether the proportion in D, E, F and G is equal. 'Proportion rationalised' uses likelihood ratios from the Bernoulli distribution to test whether an equal share is rationalised across columns $(\mathrm{df}=1)$. Note that this is equivalent to testing whether the proportion not rationalised is equal.

We find few differences between samples. For none of the comparisons in the Table do we find a significant difference between those adhering to the benchmark model and those adhering to the alternative model. The differences that we do find are in the implied magnitudes of $\gamma$, rather than in the constraint $m_{t}=0$. The contrast is strongest between participants who report they would invest or save a 1,000 PKR lump sum, and those who do not. Among those who would save or invest, we find a substantially lower preference for lumpy purchases among those with $m_{t} \geq 0$, and a substantially higher preference for lumpy purchases among those constrained to $m_{t}=0$. We also find significantly different proportion of types between participants who report receiving requests for money from family members and those who do not. But these differences are hard to rationalise - for example, more Type B and fewer Type $\mathrm{E}$ are among those who receive requests. In the other two cases, we cannot reject the null that the proportions of types are equal across subsamples. ${ }^{40}$

${ }^{40}$ We also find a significantly higher proportion of non-rationalised behaviour among those whose family members request money (compared to those who do not) and among those who report difficulty saving (compared to those who do not). 
In Table 13, we mirror the reduced form disaggregation presented in Table 9. Only a small proportion of participants can be classified as adhering to the benchmark model. These findings are in line with those reported in Table 9, but confirm that reducedform differences imply different models of behaviour. We report p-values from various hypothesis tests at the bottom of the Table. We find that the mix of types does not vary substantially by the frequency of income flows. The tests show some significant heterogeneity between columns (2) and (3): those without salaried income are significantly more likely to adhere to the predictions of the benchmark model, but the overall proportion adhering to that model remains small.

Taken together, the results confirm that the breakdown of study participants into different behavioural types is quite stable irrespective of their circumstances. This also implies that, in general, answers to survey questions are not good predictors of the type of motivation people have when saving. This motivation is better captured in the structural analysis. The only exceptions relate to:

Table 13

Structural Estimates: Disaggregating by Baseline Income Flow

\begin{tabular}{|c|c|c|c|}
\hline & \multicolumn{3}{|c|}{ Estimated proportions } \\
\hline & (1) & (2) & (3) \\
\hline Salaried income? & No & No & Yes \\
\hline Non-salaried income? & No & Yes & Yes \\
\hline Type A & $0.0 \%$ & $5.0 \%$ & $0.0 \%$ \\
\hline Type B & $4.4 \%$ & $1.6 \%$ & $4.7 \%$ \\
\hline Type C & $4.6 \%$ & $6.5 \%$ & $0.2 \%$ \\
\hline Type D & $14.2 \%$ & $4.6 \%$ & $18.0 \%$ \\
\hline Type E & $0.0 \%$ & $2.7 \%$ & $5.8 \%$ \\
\hline Type F & $16.0 \%$ & $13.0 \%$ & $8.8 \%$ \\
\hline Type G & $36.7 \%$ & $40.3 \%$ & $41.7 \%$ \\
\hline Not rationalised & $24.1 \%$ & $26.3 \%$ & $20.9 \%$ \\
\hline$N$ & 83 & 377 & 249 \\
\hline Log-likelihood & -62.145 & -261.008 & -196.646 \\
\hline Hypothesis tests: & All parameters & $\begin{array}{l}\text { Proportion } \\
\text { in } \mathrm{A}, \mathrm{B} \text { or } \mathrm{C}\end{array}$ & $\begin{array}{l}\text { Proportion } \\
\text { rationalised }\end{array}$ \\
\hline$H_{0}:$ column $(1)=$ column $(2)(p):$ & 0.561 & 0.504 & 0.682 \\
\hline$H_{0}:$ column $(1)=$ column $(3)(\mathrm{p})$ : & 0.618 & 0.395 & 0.542 \\
\hline$H_{0}:$ column $(2)=$ column $(3)(\mathrm{p})$ : & $0.013^{* *}$ & $0.054 *$ & 0.122 \\
\hline$H_{0}:$ all columns equal $(\mathrm{p}):$ & $0.089 *$ & 0.152 & 0.302 \\
\hline
\end{tabular}

Notes. This Table reports non-parametric maximum likelihood estimates from the mixture model, disaggregated by binary baseline covariates. 'Types' refer to Table 10. 'Not rationalised' means that an individual did not behave as any of the types predict. The last panel of the Table reports likelihood ratio tests to compare estimates between columns. 'All parameters' refers to tests of whether the proportion of each type are common between columns $(\mathrm{df}=6$ for the first three tests; $\mathrm{df}=12$ for the final test). 'Proportion in $\mathrm{A}, \mathrm{B}$ or C' tests whether the proportion adhering to the benchmark model is equal across columns ( $\mathrm{df}=1$ for the first three tests; $\mathrm{df}=2$ for the final teste). Note that this is equivalent to testing whether the Proportion in $\mathrm{D}, \mathrm{E}, \mathrm{F}$ and $\mathrm{G}$ is equal. 'Proportion rationalised' uses likelihood ratios from the Bernoulli distribution to test whether an equal share is rationalised across columns $(\mathrm{df}=1$ for the first three tests; $\mathrm{df}=2$ for the final teste). Note that this is equivalent to testing whether the proportion not rationalised is equal.

(C) 2017 Royal Economic Society. 
(i) individuals who earn both daily and monthly income; and

(ii) individuals who report wanting to save or invest.

Both categories exhibit a higher demand for lump-sum accumulation - perhaps because they have a higher income. These are also the households who, according to theory, are most interested in the commitment saving aspect of our product.

\subsection{Structural Results: Robustness}

We run three robustness checks on the structural model. First, we consider the possibility that, in anticipation of receiving the 1,100 PKR show-up fee, respondents may deviate from their usual strategy and refuse offers in the third period. To test this, we add additional types as follows: for each of the types in Table 10, we introduce a new 'star' type to capture respondents who refuse all contracts offered in the final round. For example, Type A accepts in rounds 1, 2 and 3 if and only if $r=0.1$ and $p=1$ while Type $A \star$ does the same in rounds 1 and 2 and always rejects in round $3 .^{41}$

Table 14 shows the results. The key conclusions do not change: if anything, allowing for 'star' types only strengthens our earlier conclusions. We now find that about $75 \%$ of

Table 14

Structural Estimates: Allowing Automatic Refusal in Wave 3

\begin{tabular}{|c|c|c|c|}
\hline \multirow[b]{2}{*}{ Type } & \multirow{2}{*}{$\begin{array}{l}\text { Estimated } \\
\text { proportion }\end{array}$} & \multicolumn{2}{|c|}{$95 \%$ confidence } \\
\hline & & Lower & Upper \\
\hline Type A & $0.0 \%$ & $0.0 \%$ & $3.3 \%$ \\
\hline Type A* & $1.2 \%$ & $0.0 \%$ & $5.7 \%$ \\
\hline Type B & $3.4 \%$ & $0.0 \%$ & $5.9 \%$ \\
\hline Type $B^{\star}$ & $0.0 \%$ & $0.0 \%$ & $3.6 \%$ \\
\hline Type C & $2.6 \%$ & $0.0 \%$ & $5.7 \%$ \\
\hline Type $C^{\star}$ & $1.1 \%$ & $0.0 \%$ & $4.9 \%$ \\
\hline Type D/D* & $10.4 \%$ & $6.1 \%$ & $13.8 \%$ \\
\hline Type E & $2.5 \%$ & $0.6 \%$ & $4.8 \%$ \\
\hline Type E* & $0.9 \%$ & $0.0 \%$ & $2.6 \%$ \\
\hline Type F & $8.7 \%$ & $5.7 \%$ & $12.0 \%$ \\
\hline Type $F \star$ & $4.6 \%$ & $2.2 \%$ & $7.0 \%$ \\
\hline Type G & $41.5 \%$ & $37.7 \%$ & $45.4 \%$ \\
\hline Type $G^{\star}$ & $9.0 \%$ & $6.6 \%$ & $11.5 \%$ \\
\hline Not rationalised & $14.1 \%$ & $11.4 \%$ & $16.9 \%$ \\
\hline$N$ & 709 & & \\
\hline Log-likelihood & -749.576 & & \\
\hline
\end{tabular}

Notes. This Table reports non-parametric maximum likelihood estimates from the mixture model. This augments the estimates in Table 11 by allowing some respondents to behave according to the structural model in waves 1 and 2, then refuse automatically in wave 3; this is denoted by the addition of ' $\star$ '. 'Types' refer to Table 10. 'Not rationalised' means that an individual did not behave as any of the types predict. $95 \%$ confidence intervals are obtained from a bootstrap with 1,000 replications.

41 The model remains identified under this extension: $\operatorname{rank}(\boldsymbol{X})=T=13$. 
respondents act as if they are constrained in holding cash between periods (that is, types $\mathrm{D}, \mathrm{D}^{\star}$ and onwards) and over $60 \%$ of respondents also have a preference for lump-sum accumulation (that is, types $\mathrm{E}, \mathrm{E} \star$ and onwards).

Second, we split the mixture model to run it separately for:

(i) a pooled sample across waves 1 and 2; and

(ii) a pooled sample across waves 2 and 3 .

We use a naive Bayes classifier, assigning each respondent her most likely type, given the estimates of the mixture model (Frühwirth-Schnatter, 2006). Of the 575 respondents whose behaviour can be rationalised in both estimated models, 450 (i.e. almost $80 \%$ ) received the same classification in both. We interpret this as reassurance that it is reasonable to pool all three waves in the same structural estimation. ${ }^{42}$ The cross-tabulation is presented in the online Appendix.

Third, we consider the possibility that some respondents are playing randomly - as if tossing a coin to decide whether to accept or not, rather than behaving according to any the types that we have modelled. To test this, we allow an additional type, whose respondents accept every offer with $50 \%$ probability. ${ }^{43}$ Table 15 shows the results. By allowing for this additional type, we can now rationalise all observed play. Previously, we were unable to rationalise the behaviour of $24 \%$ of respondents. We now estimate that $40 \%$ of respondents are playing randomly. This is an interesting result in its own right. One possibility is that some of these participants do not have stable preferences

Table 15

Structural Estimates: Allowing a Type with Random Play

\begin{tabular}{lcrr}
\hline \hline & & \multicolumn{2}{c}{$95 \%$ confidence } \\
\cline { 3 - 4 } Type & $\begin{array}{c}\text { Estimated } \\
\text { proportion }\end{array}$ & Lower & Upper \\
\hline Type A & $0.9 \%$ & $0.0 \%$ & $5.7 \%$ \\
Type B & $0.8 \%$ & $0.0 \%$ & $4.1 \%$ \\
Type C & $4.5 \%$ & $0.1 \%$ & $7.5 \%$ \\
Type D & $8.3 \%$ & $3.8 \%$ & $11.7 \%$ \\
Type E & $0.0 \%$ & $0.0 \%$ & $3.3 \%$ \\
Type F & $8.5 \%$ & $4.9 \%$ & $11.9 \%$ \\
Type G & $36.6 \%$ & $32.5 \%$ & $41.0 \%$ \\
Random play & $40.5 \%$ & $35.0 \%$ & $45.6 \%$ \\
Not rationalised & $0.0 \%$ & $0.0 \%$ & $0.0 \%$ \\
$N$ & 709 & & \\
Log-likelihood & $-1,183.7$ & & \\
\hline \hline
\end{tabular}

Notes. This Table reports non-parametric maximum likelihood estimates from the mixture model. This augments the estimates in Table 11 by introducing a type that decides to accept or reject by tossing a fair coin in each wave. 'Types' refer to Table 10. 'Not rationalised' means that an individual did not behave as any of the types predict. $95 \%$ confidence intervals are obtained from a bootstrap with 1,000 replications.

\footnotetext{
42 It would be erroneous to conclude from this evidence that the remaining 125 individuals switch types between waves; the naive Bayes classifier is crude in that it assigns the single most likely type to each individual, rather than allowing for a probabilistic distribution across types. For this reason, it is possible for an individual of a fixed type to be classified in two different ways in two different samples.

43 The model remains identified under this extension, too: $\operatorname{rank}(\boldsymbol{X})=T=8$.
} 
across rounds - for instance because their desire for lump-sum accumulation varies over time. In the absence of exogenous time-varying variation in the determinants of preference for lump-sum accumulation (and other preference shifters), we unfortunately have no way of investigating this formally. Another possibility is that some participants regard the experiment as a form of entertainment and make decisions that are not determined by deep preferences. While we cannot rule out this possibility entirely, it is unlikely to play a big role here: not only are participants sufficiently poor to care about the monetary amounts at stake in the experiment, the study takes place over several weeks and is run by NRSP, an organisation from which they receive regular loans. From this we suspect that the contextual frame of the experiment reduces the likelihood of careless play. One remaining possibility is that random play is due to poor understanding of the type of financial product we offered. As discussed earlier, this is not what participants reported at the end of the experiment. Nonetheless, as discussed in subsection 2.2, we conducted a survey in mid-2016 to check understanding of the product among our original respondents, and found widespread familiarity with such a contract; this is not surprising given that they mimic the well-known local 'committee' institution. Other results do not change substantively: almost $50 \%$ of respondents act as if they are constrained in holding cash (Types D, E, F and G), and that about $45 \%$ of respondents also have a preference for lump-sum accumulation (types E, F and $\mathrm{G}$ ).

\section{Conclusions}

In this article, we introduce a new framed field experiment to distinguish between demand for microcredit and demand for microsaving. Traditional models often predict that people should either demand to save or demand to borrow. This, however, is emphatically not what the results show. Rather, we find a high demand both for saving and for credit - even among the same respondents at one or two weeks interval. We hypothesise that saving and borrowing are substitutes for many microfinance clients, satisfying the same underlying demand for lump-sum accumulation via regular deposits. We test this hypothesis using a new structural methodology with maximal heterogeneity; the results confirm that a clear majority of respondents have high demand for lump-sum accumulation while also struggling to hold cash over time. This result has potential implications for future academic research and for the design of more effective microfinance products.

Although we do find sizeable demand for our product from households deriving all their income from salaries paid at regular intervals, take-up was nonetheless lower among them. We indeed expect less interest in daily instalments among salaried workers because they can use their monthly or bi-weekly pay to finance lump-sum expenditures of the magnitude covered by the experiment. But these households may nonetheless have pent up demand for commitment saving instruments with a longer horizon - e.g., to save for retirement or set up a college fund for their children. Such financial instruments are indeed offered in many developed economies, either by commercial banks (e.g. saving set-aside), by life insurance institutions, or as part of government or employer-sponsored programs.

Regarding the external validity of the results, we can offer some evidence from subsequent work we conducted in Pakistan. We conducted an experiment with a (C) 2017 Royal Economic Society. 
similar subject population in the same region of Pakistan. The design of the microfinance product offered is identical, but instalments are due weekly instead of daily. With weekly instalments, take-up falls by more than half compared to the experiment presented in this paper. Further, the large fall in take-up occurred even though we set the weekly deposit amount at 500 PKR only, compared to 200 PKR daily deposit in this experiment (i.e., less than half the amount of savings mobilisation per week). Even more striking: we investigate the possibility of offering a similar microfinance product with a monthly instalment. When we floated the idea to the subject population, we were told that the maximum monthly deposit that would generate any enthusiasm in the product would be of the order of 1,000 PKR. In other words, less than a quarter the savings per month than could be mobilised through daily instalments. While this final evidence is only impressionistic, it is consistent with the idea that the study population has pent up demand for savings and credit products with daily instalments, something that is perfectly consistent with:

(i) having frequent cash inflows; and

(ii) finding it difficult to save at home.

This also explains why participants take up a daily instalment product even though they also receive medium-term loans with monthly instalments from the MFI. The reason is that our product serves a different purpose, namely, to accumulate small lump-sums from cash inflows that vary day to day. For that purpose, credit and savings are largely equivalent in the eyes of the study population.

Lahore School of Economics

Milan Politecnico

Stanford University

University of Oxford

Lahore School of Economics

Accepted: 31 January 2017

Additional Supporting Information may be found in the online version of this article:

Appendix A. Construction of the Variables and Balance of Randomisation.

Appendix B. Breach of Experimental Protocol.

Appendix C. Further Regressions.

Appendix D. Time and Attrition.

Appendix E. Take-up by Staff Member and Location.

Appendix F. Solving the Structural Model Numerically.

Data S1.

\section{References}

Adams, D. and Canavesi de Sahonero, M. (1989). 'Rotating savings and credit associations in Bolivia', Savings and Development, vol. 13(3), pp. 219-36.

Aliber, M. (2001). 'Rotating savings and credit associations and the pursuit of self-discipline: a case study in South Africa', African Review of Money, Finance and Banking, pp. 51-73. 
Ambec, S. and Treich, N. (2007). 'Roscas as financial agreements to cope with self-control problems', Journal of Development Economics, vol. 82(1), pp. 120-37.

Ananth, B., Karlan, D. and Mullainathan, S. (2007). 'Microentrepreneurs and their money: three anomalies', Working Paper, Financial Access Initiative and Innovations for Poverty Action.

Andersen, S., Harrison, G.W., Lau, M.I. and Rutström, E.E. (2008). 'Eliciting risk and time preferences', Econometrica, vol. 76(3), pp. 583-618.

Andersen, S., Harrison, G.W., Lau, M.I. and Rutström, E.E. (2014). 'Discounting behavior: a reconsideration', European Economic Review, vol. 71, pp. 15-33.

Anderson, S. and Baland, J.M. (2002). 'The economics of ROSCAs and intrahousehold resource allocation', Quarterly Journal of Economics, vol. 117(3), pp. 963-95.

Armendáriz de Aghion, B. and Morduch, J. (2005). The Economics of Microfinance, Cambridge, MA: The MIT Press.

Aryeetey, E. and Steel, W. (1995). 'Savings collectors and financial intermediation in Ghana', Savings and Development, vol. 19(2), pp. 189-99.

Aryeetey, E. and Udry, C. (1997). 'The characteristics of informal financial markets in sub-Saharan Africa', Journal of African Economies, vol. 6(1), pp. 161-203.

Ashraf, N., Gons, N., Karlan, D. and Yin, W. (2003). 'A review of commitment savings products in developing countries', ERD Working Paper No. 45.

Ashraf, N., Karlan, D. and Yin, W. (2006). 'Tying Odysseus to the mast: evidence from a commitment savings product in the Philippines', Quarterly Journal of Economics, vol. 121 (2), pp. 635-72.

Baland, J.M., Guirkinger, C. and Mali, C. (2011). 'Pretending to be poor: borrowing to escape forced solidarity in Cameroon', Economic Development and Cultural Change, vol. 60(1), pp. 1-16.

Banerjee, A., Duflo, E., Glennerster, R. and Kinnan, C. (2015). 'The miracle of microfinance? Evidence from a randomized evaluation', American Economic Journal: Applied Economics, vol. 7(1), pp. 22-53.

Basu, K. (2016). 'A behavioral model of simultaneous borrowing and saving', Oxford Economic Papers, vol. 68(4), pp. 1166-74.

Bauer, M., Chytilová, J. and Morduch, J. (2012). 'Behavioral foundations of microcredit: experimental and survey evidence from rural India', American Economic Review, vol. 102(2), pp. 1118-39.

Bernheim, B.D., Ray, D. and Yeltekin, Ş. (2015). 'Poverty and self-control', Econometrica, vol. 83(5), pp. 1877911.

Besley, T.J., Coate, S. and Loury, G.C. (1993). 'The economics of rotating savings and credit associations', American Economic Review, vol. 83(4), pp. 792-810.

Brune, L., Giné, X., Goldberg, J. and Yang, D. (2016). 'Facilitating savings for agriculture: field experimental evidence from Malawi', Economic Development and Cultural Change, vol. 64(2), pp. 187-220.

Burgess, R. and Pande, R. (2005). 'Do rural banks matter? Evidence from the Indian Social Banking experiment', American Economic Review, vol. 95(3), pp. 780-95.

Camerer, C., Babcock, L., Loewenstein, G. and Thaler, R. (1997). 'Labor supply of New York City cabdrivers: one day at a time', Quarterly Journal of Economics, vol. 112(2), pp. 407-41.

Coller, M. and Williams, M.B. (1999). 'Eliciting individual discount rates', Experimental Economics, vol. 2(2), pp. $107-27$.

Collins, D., Morduch, J., Rutherford, S. and Ruthven, O. (2009). Portfolios of the Poor: How the World's Poor Live on $\$ 2$ a Day, Princeton, NJ: Princeton University Press.

Dehejia, R., Montgomery, H. and Morduch, J. (2012). 'Do interest rates matter? Credit demand in the Dhaka Slums', Journal of Development Economics, vol. 97(2), pp. 437-49.

DellaVigna, S. and Malmendier, U. (2006). 'Paying not to go to the gym', American Economic Review, vol. 96(3), pp. 694-719.

Dohmen, T., Falk, A., Huffman, D. and Sunde, U. (2012). 'Interpreting time horizon effects in inter-temporal choice', IZA Discussion Paper No. 6385.

Dupas, P. and Robinson, J. (2013). 'Why don't the poor save more? Evidence from health savings experiments', American Economic Review, vol. 103(4), pp. 1138-71.

Field, E., Pande, R., Papp, J. and Rigol, N. (2013). 'Does the classic microfinance model discourage entrepreneurship among the poor? Experimental evidence from India', American Economic Review, vol. 103(6), pp. 2196-226.

Frühwirth-Schnatter, S. (2006). Finite Mixture and Markov Switching Models, New York, NY: Springer Science \& Business Media.

Goldberg, J. (2011). 'The lesser of two evils: the roles of social pressure and impatience in consumption decisions', mimeo, University of Maryland.

Gross, D.B. and Souleles, N.S. (2002). 'Do liquidity constraints and interest rates matter for consumer behavior? Evidence from credit card data', Quarterly Journal of Economics, vol. 117(1), pp. 149-85.

Gugerty, M.K. (2007). 'You can't save alone: commitment in rotating savings and credit associations in Kenya', Economic Development and Cultural Change, vol. 55(2), pp. 251-82.

Handa, S. and Kirton, C. (1999). 'The economics of rotating savings and credit associations: evidence from the Jamaian 'Partner', Journal of Development Economics, vol. 60(1), pp. 173-94. 
Haq, A., Aslam, A., Chaudhry, A.A., Naseer, A., Muhammad, K., Mushtaq, K. and Saleem, M.F. (2013). 'Who is the 'Arthi': understanding the commission agent's role in the agriculture supply chain', Working Paper, IGC.

Islam, M.T., Takanashi, C. and Natori, T. (2013). 'Big challenges by a small microfinance institution: a case study of Safesave Bangladesh from the customer satisfaction and ICT introduction perspective', International Journal of Business and Management, vol. 8(14), pp. 23-35.

John, A. (2015). 'When commitment fails - evidence from a regular saver product in the Philippines', Working Paper, ENSAE, Paris.

Kaplan, G., Violante, G. and Weidner, J. (2014). 'The wealthy hand-to-mouth', Brookings Papers on Economic Activity, vol. Spring, pp. 77-138.

Karlan, D. and Zinman, J. (2011). 'Microcredit in theory and practice: using randomized credit scoring for impact evaluation', Science, vol. 332(6035), pp. 1278-84.

Kast, F. and Pomeranz, D. (2014). 'Saving more to borrow less: experimental evidence from access to formal savings accounts in Chile', Working Paper No. 14-001, Harvard Business School.

Kaur, S., Kremer, M. and Mullainathan, S. (2015). 'Self control at work', Journal of Political Economy, vol. 123 (6), pp. 1227-77.

Kedir, A. and Ibrahim, G. (2011). 'ROSCAs in Urban Ethiopia: are the characteristics of the institutions more important than those of members?', Journal of Development Studies, vol. 47(7), pp. 998-1016.

Kovsted, J. and Lyk-Jensen, P. (1999). 'Rotating savings and credit associations: the choice between random and bidding allocation of funds', Journal of Development Economics, vol. 60(1), pp. 143-72.

Laureti, C. (2015). 'The debt puzzle in Dhaka's slums: do poor people co-hold for liquidity needs?', Paper No. 15/021, Centre Emile Bernheim Working.

McKinnon, R.I. (1973). Money and Capital in Economic Development, Washington, DC: Brookings Institution.

Morduch, J. (2010). 'Borrowing to save', Journal of Globalization and Development, vol. 1(2), pp. 1-11.

Mullainathan, S. and Shafir, E. (2009). 'Savings policy and decision-making in low-income households', in (M. Barr and R. Blank, eds.), Insufficient Funds: Savings, Assets, Credit and Banking Among Low-income Households, pp. 121-46, New York, NY: Russell Sage Foundation.

Platteau, J.P. (2000). Institutions, Social Norms, and Economic Development, vol. 1, Amsterdam: Harwood Academic Publishers.

Rutherford, S. (1997). 'Informal financial services in Dhaka's slums', in (G. Wood and I. Sharif, ed.), Who Needs Credit? Poverty and Finance in Bangladesh, Chapter 16. Dhaka: Dhaka University Press.

Rutherford, S. (2000). The Poor and Their Money, Oxford: Oxford University Press.

Schilbach, F. (2017). 'Alcohol and self-control: a field experiment in India', Working Paper, Available at: http:/ /economics.mit.edu/files/10649.pdf (last accessed: 19 July 2017).

Somville, V. (2011). 'Daily collectors, public good provision and private consumption: theory and evidence from urban Benin', Working Paper No. 1106, Univerity of Namur Department of Economics.

Somville, V. (2014). 'Informal savings and intra-household strategies: theory and evidence from urban Benin', mimeo, Namur University.

Stahl, D.O. and Wilson, P.W. (1995). 'On players' models of other players: theory and experimental evidence', Games and Economic Behavior, vol. 10(1), pp. 218-54.

Steel, W., Aryeetey, E., Hettige, H. and Nissanke, M. (1997). 'Informal financial markets under liberalization in four African countries', World Development, vol. 25(5), pp. 817-30.

Tanaka, T. and Nguyen, Q. (2010). 'ROSCA as a saving commitment device for sophisticated hyperbolic discounters: field experiment from Vietnam', Working Paper.

Von Gaudecker, H.M., Van Soest, A. and Wengström, E. (2011). 'Heterogeneity in risky choice behavior in a broad population', American Economic Review, vol. 101(2), pp. 664-94. 